\title{
(4) \\ The Externality of Vacant Houses: The Case of Toshima Municipality, Tokyo, Japan *
}

\author{
Taisuke Sadayuki, ${ }^{a, b}$ Yuki Kanayama, ${ }^{c}$ and Toshi H. Arimurab,d \\ ${ }^{a}$ Faculty of Economics, Seijo University, Japan \\ ${ }^{b}$ Research Institute for Environmental Economics and Management, Waseda University, Japan \\ ${ }^{c}$ Graduate School of Economics, Waseda University, Japan \\ ${ }^{d}$ Faculty of Political Science and Economics, Waseda University, Japan
}

\begin{abstract}
The Japanese housing market has experienced a rapid increase in the number of vacant housing units due to regulatory obstacles and a decreasing population. Abandoned vacant houses can cause negative externalities in the surrounding neighborhood, due to illegal dumping of garbage, increased risks of arson, and building collapse. Few empirical studies exist that focus on the negative externalities of vacant houses, because of data limitations. This paper investigates these negative externalities by using a complete field survey conducted in the Toshima municipality, one of 23 wards in the Tokyo prefecture. We find that a vacant (single-family) house devalues nearby rental prices by 1-2 percent, on average. Vacant houses with property defects cause greater spillover effects. Addressing dilapidated vacant housing with overgrown vegetation and combustible materials would likely produce annual tax gains greater than one million yen (approximately nine thousand U.S. dollars) per vacant housing unit. Given the substantial number of existing vacant houses, local governments should identify the types of vacant houses causing the most severe negative externalities based on empirical assessment and implement efficient countermeasures to address the issue.
\end{abstract}

Keywords: hedonic, externality, house price, vacant house, dilapidated house, property tax

JEL Codes: D62, H23, R11, R21, R51

*This work is supported by the Toshima municipality, the Research Institute for Environmental Economics
and Management (RIEEM) at Waseda University, JSPS KAKENHI Grant Number 19K13697, and Joint Re-
search Program No. 470 at CSIS University of Tokyo. The authors are grateful to the Toshima municipality
for providing valuable data, editor Dr. Amanda Ross and anonymous referees for helpful comments, and
Naonari Yajima for research assistance. The views expressed in the paper are solely those of the authors, and
neither represent those of the organizations to which the authors belong. Taisuke Sadayuki is an Associate
Professor at Seijo University, Tokyo, Japan. Yuki Kanayama was a graduate student at Waseda University,
Tokyo, Japan, when he worked on this paper. Toshi H. Arimura is a Professor at Waseda University, Tokyo,
Japan, and a director of Research Institute for Environmental Economics (RIEEM) at Waseda University.
Corresponding Author: Taisuke Sadayuki, E-mail: tai.sadayuki@gmail.com.

(c) Southern Regional Science Association 2020

ISSN 1553-0892, 0048-49X (online)

www.srsa.org/rrs 


\section{INTRODUCTION}

The Japanese housing market has experienced a drastic increase in both the volume of vacant housing and in vacancy rates (Figure 1), because of an aging population and regulatory obstacles. ${ }^{1}$ The number of vacant housing units reached almost 8.5 million in 2018. The national vacancy rate has more than tripled in the last 50 years and reached 13.6 percent in 2018 , becoming among the highest in the world. ${ }^{2}$

Inadequately managed vacant housing can be a source of negative externalities for the surrounding neighborhood due to the illegal dumping of garbage, disturbed landscape, increased risks of arson, building collapse, fire hazards, and crime (Cohen, 2001; Schilling, 2002; Department for Communities and Local Government, 2007). In Japan, approximately 22 percent of vacant housing units are vandalized and this ratio is as high as 30 percent for single-family vacant houses. ${ }^{3}$ According to a survey of municipalities conducted by the Ministry of Land and Transport in 2009, ${ }^{4}$ approximately three-quarters of local authorities responding to the questionnaire reported that vacant housing and vacant lots in their municipalities harmed the landscape and decreased security in neighborhoods. Of responding municipalities, 20 percent experienced issues of illegal dumping of garbage and and 36 percent experienced arson in vacant houses. Potential buyers and renters may only be willing to pay a lower amount to live near vacant houses than to live in a neighborhood without any vacant houses.

To address the increasing number of vacant housing units, the Japanese government enacted the Act on Special Measures Concerning Vacant Houses in 2015, which allows local governments to increase property tax rates on and even force the demolition of vacant houses that cause serious negative externalities or are at risk of building collapse. ${ }^{5}$ Local governments have also gradually begun to establish vacant housing ordinances and attempted

\footnotetext{
${ }^{1}$ Two factors have largely contributed to the recent increase in the vacancy rate in Japan. One is the excessive housing supply and subsidies despite recent depopulation. Because most housing properties owned by elderly people are old and have a low market value, many family members are reluctant to manage or inherit these properties. The other factor is Japan's tax system. Once a building is demolished, the new property taxes levied on the land are six times higher than those previously levied, which reduces the incentive of owners to demolish their properties.

${ }^{2}$ The estimated vacancy rates were approximately 11.5 percent in the U.S. in $2017,8.7$ percent in Canada in 2016, 4.5 percent in Germany in 2011, 0.89 percent in the UK in 2018 (according to OECD Questionnaire on Affordable and Social Housing in 2019, available at http://oe.cd/ahd), 5 percent in Singapore in 2008 and 7 percent in Taiwan in 2000 (according to a report published in 2013 by The Real Estate Transaction Promotion Center, available in Japanese at https://www.retpc.jp/consul/overseas_research/). Immergluck (2016) provides a helpful description of the trend of housing vacancy in the U.S.

${ }^{3}$ These statistics are based on visual assessments by investigators from the Housing and Land Survey in 2013 conducted by the Ministry of Internal Affairs and Communications.

${ }^{4}$ The report from the survey, written in Japanese, can be found at https://www.mlit.go.jp/common/ 000042301.pdf (Retrieved on Jan 22 $2^{\text {nd }}, 2020$ ).

${ }^{5}$ England enacted similar laws for vacant houses in 2006, namely, the Empty Dwelling Management Orders (EDMOs), which allow local governments to take over the management of vacant properties upon court approval. Contrary to the situation in Japan - with an excess housing stock coupled with a declining population - England has been facing housing shortages due to the continuing population growth. To promote the reuse of a substantial number of abandoned vacant houses, England has also removed the previous property tax discount given to owners of vacant houses (?).
}

(c) Southern Regional Science Association 2020. 


\section{Figure 1: Number and Rate of Vacant Housing Units in Japan}

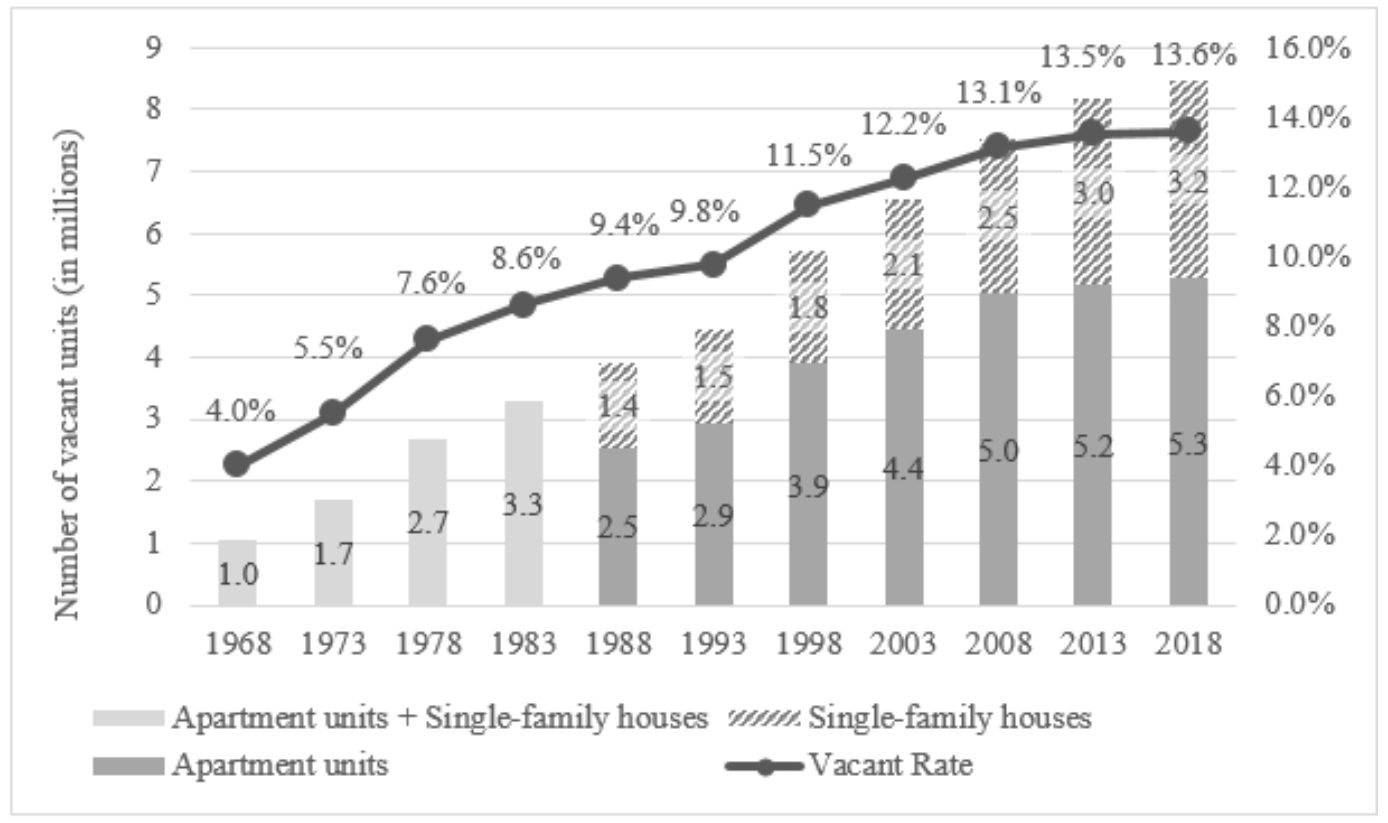

Source: Housing and Land Survey conducted by the Ministry of Internal Affairs and Communications

various measures, such as partially subsidizing the costs of demolition and renovation of old buildings, listing vacant houses whose owners are willing to sell or rent, and desterilizing unused properties for use as guest houses and places for public use. Exercising these measures, however, can involve enormous time and costs, including finding the owners of vacant houses and negotiating with various stakeholders to determine how to manage the properties. $^{6}$ Given restricted public financing and personnel resources, it is important for local governments to assess the impact of vacant houses quantitatively and implement efficient countermeasures by targeting those properties causing serious negative externalities.

This paper aims to estimate the impact of vacant (single-family) houses on neighborhood property values in the Toshima municipality in Tokyo and assess the potential increase in property tax revenue from neighboring properties that would result from addressing vacant houses. The results suggest that, on average, the presence of a vacant house is associated with an effect on units within $50 \mathrm{~m}$ (0.031 mile). We also detect some heterogeneity in the degree of the externality depending on the physical conditions of vacant houses. In particular, addressing dilapidated vacant houses such as those with overgrown trees and combustible materials left on the property can ameliorate the negative externality and increase the municipality's property tax revenue enormously.

\footnotetext{
${ }^{6}$ Although property owners are supposedly tracked by property titles, finding an owner of a vacant house can sometimes require substantial effort because the records are not necessarily kept up-to-date by the owners. Even if owners are identified, many are reluctant to address the problem and painstaking conversations among the owner, family members, real estate agencies, and other mediators, such as local public authorities and nonprofit organizations, are required to determine how to manage the property.
}

(C)Southern Regional Science Association 2020. 
We found three studies that empirically assessed the impact of vacant houses on neighboring property values (i.e., Mikelbank (2008); Whitaker and Fitzpatrick IV (2013); Awazu (2014)). Our study makes three main contributions to the existing literature. First, although the previous studies examined the impact of vacant houses on neighboring sale or assessment prices, our research provides the first empirical evidence of the impact on the rental housing market in a neighborhood. The rental price reflects the quality of housing services, whereas sale price is, in theory, the expected discounted value of the rental revenue in the future. Thus, using rental housing enabled us to avoid the problems associated with expectations of the future and focus on the current quality of dwellings.

Second, we use finer regional fixed effects than the previous studies and additional regional characteristics in the estimation to separate the externality from confounding area-specific effects. The estimated externalities of vacant and dilapidated houses in the previous studies appear to be quite large in magnitude. ${ }^{7}$ We suspect that regional unobservable effects may not be sufficiently addressed in these studies such that the estimates reflect not only the externality of dilapidated houses or vacant houses, but also the fact that the unattractiveness of the neighborhood leads to more dilapidated or vacant houses. In this research, we use 81 regional dummy variables, each of which controls for the neighborhood fixed effect of an area of approximately 160,000 square meters (approximately 0.062 square mile) on average. ${ }^{8}$

Furthermore, dummy variables representing the land-use classification and proximity to nearby apartment buildings with high vacancy rates are included in the hedonic estimation to distinguish area-specific effects that cannot be addressed by the regional dummy variables alone. Our result shows a much smaller, but still statistically significant, negative externality relative to the other studies. ${ }^{9}$

Lastly, we estimate the possible heterogeneity in the externality in relation to the physical conditions of the vacant (single-family) houses. Then, we assess the potential property tax revenue increase that would result from addressing vacant houses in each condition. In particular, we find that vacant houses with the presence of overgrown vegetation or combustible materials on the property contribute to large reductions in nearby rental prices. Estimates suggest that addressing these vacant houses would increase the annual property tax income by more than one million yen per vacant house (approximately 9,000 U.S. dollars per vacant house, with an assumed exchange rate of 110 yen to the dollar). Although heterogeneity of vacant housing externalities has been examined previously (Awazu, 2014), this paper is

\footnotetext{
${ }^{7}$ The estimated negative externalities are 4 percent within $76.2 \mathrm{~m}$ (0.047 mile) in Mikelbank (2008), 2 percent within $152.4 \mathrm{~m}$ (0.095 mile) in Whitaker and Fitzpatrick IV (2013), and 10 percent within $90 \mathrm{~m}$ (0.056 mile) or less in Awazu (2014) for vacant houses and 9 percent within $80.5 \mathrm{~m}$ (0.050 mile) in Paredes and Skidmore (2017) for dilapidated houses.

${ }^{8} \mathrm{~A}$ mean area for which a regional fixed effect is controlled for in Paredes and Skidmore (2017) is 7,250,000 square meters. No neighborhood fixed effect is included in Mikelbank (2008), Whitaker and Fitzpatrick IV (2013), and Awazu (2014) for their cross-sectional analyses. However, Awazu (2014) finds much smaller negative impacts when he uses panel data and includes location fixed effects to evaluate the change in appraised land prices after the owners of nearby dilapidated vacant houses were advised by the local authority to make an improvement. Whitaker and Fitzpatrick IV (2013) report that addressing census-track fixed effects as a robustness check resulted in estimates that were between one-fifth and one-half lower in magnitude.

${ }^{9}$ In our analysis, the exclusion of regional fixed effects, as in Awazu (2014), amplifies the estimated magnitude of negative externalities by approximately $30-50$ percent.
}

(c) Southern Regional Science Association 2020. 
the first to provide an evidence-based justification for publicly funded countermeasures by assessing the effect of addressing vacant houses on property tax revenue.

The next section reviews the previous empirical literature on vacant houses. The following two sections explain the data and empirical strategy. Then, the estimation results are discussed, followed by concluding remarks.

\section{LITERATURE REVIEW}

Three studies have examined the impact of vacant houses on neighboring property values (Mikelbank, 2008; Whitaker and Fitzpatrick IV, 2013; Awazu, 2014). Mikelbank (2008) analyzes data from Columbus, Ohio and finds that a vacant house is associated with a 4 percent reduction in the price of properties within $250 \mathrm{ft}(76.2 \mathrm{~m})$. Whitaker and Fitzpatrick IV (2013) examine the external effect of both foreclosed properties and vacant properties together by using data from Cuyahoga County, Ohio, and reveal that a vacant, nonforeclosed property reduces the prices of housing within $500 \mathrm{ft}(152.4 \mathrm{~m})$ by 2 percent on average, while the negative impact becomes 3 percent in areas with lower poverty rates. Awazu (2014) analyzes cross-sectional data on assessed land prices in Tokorozawa City in Saitama, Japan and finds that the assessed land price near a dilapidated vacant property is approximately 10 percent lower than that of land that is not near such properties. In addition, Paredes and Skidmore (2017) analyze unique cross-sectional survey data from Detroit, Michigan and estimate that each additional dilapidated house and vacant lot is associated with a 9 percent and 5 percent reduction, respectively, in the price of properties within 0.05 miles $(80.5 \mathrm{~m})$.

Such empirical studies on the external effects of vacant houses are scarce relative to studies focusing on the determinants of housing abandonment ${ }^{10}$ due to a lack of the information necessary to conduct an analysis. There are several critical reasons why it is difficult to obtain sufficient data on vacant houses. For instance, the assessment of the spatial externality of vacant houses requires detailed information on the occupancy of all properties in the study area (i.e., a complete survey covering all units, rather than a sampling survey). ${ }^{11}$

\footnotetext{
${ }^{10}$ The studies on the determinants of housing abandonment include Bender (1979), White (1986), Arsen (1992), Scafidi et al. (1998), Hillier et al. (2003), Zhang (2012), Morckel (2013, 2014a,b), and Baba and Hino (2019). In theory, a higher ratio of property tax payment to property value is expected to increase the probability of housing abandonment. White (1986) and Arsen (1992) use neighborhood-level data in New York City and find a positive correlation, while Bender (1979) uses Chicago data and does not find such a correlation. More recently, Morckel (2013, 2014a,b) use neighborhood-level data in Ohio to investigate the determinants of housing abandonment and find three main driving factors of housing abandonment, namely, market conditions, gentrification, and physical neglect. The studies also reveal the presence of spatial spillover effects. Some other studies use detailed property-level data to further examine the relationships between property attributes and housing abandonment. For instance, Hillier et al. (2003) statistically identify several housing attributes that are correlated with abandonment, such as whether a property was vacant, had outstanding housing code violations, and had tax arrearages. Scafidi et al. (1998) use financial information on residential properties in New York City and find an economically and statistically significant positive correlations between the probability of abandonment and the outstanding lien-to-market-value ratio. Baba and Hino (2019) examine the determinants of abandonment among vacant houses in Kawaguchi City in Saitama, Japan. A vacant house is more likely to be abandoned if it is old, on a narrow road, the residential area has a high floor area, the owner is unknown or lives far away, or inherited after the death of the previous occupant.

${ }^{11}$ In general, a survey of vacant houses conducted by the government, such as the Housing and Land Survey
} 
The abovementioned studies on the externalities of vacant and dilapidated houses as well as the present research are supported by the few local public authorities who have initiated large-scale surveys. ${ }^{12}$ The other reason is that constructing a panel dataset for vacant houses is difficult because determining the timing of vacancies for each property is extremely challenging. In fact, the main results of all the abovementioned studies on the externality of vacant houses (i.e., Mikelbank (2008); Whitaker and Fitzpatrick IV (2013); Awazu (2014)) are based on a cross-sectional type of analysis. Awazu (2014) also conducts an additional regression using panel data on appraised land prices surrounding vacant houses and finds that the price of land near dilapidated vacant houses increases once the city office receives a consultation by general citizens regarding the vacant house.

In contrast to the few empirical assessments focusing on vacant housing externalities, many studies have investigated the externality of foreclosures, given the availability and completeness of data on foreclosed housing (to name a few, Harding et al. (2009); Campbell et al. (2011); Gerardi et al. (2015); Zhang et al. (2016); Bak and Hewings (2017)). In many cases, foreclosed houses are likely to be vacant from the time the house is seized until the time the house is purchased by a new owner. Most studies find a negative relationship between the presence of foreclosures and the prices of nearby properties, but this correlation does not necessarily indicate the magnitude of the negative externality of nonforeclosed vacant houses, because of the confounding factors associated with foreclosed houses (Whitaker and Fitzpatrick IV, 2013). In relation to the externality of vacant houses, Boessen and Chamberlain (2017) use census tract data to assess the impact of nonforeclosed vacant properties on crime in Cleveland, Ohio. They find that, relative to the impact of foreclosures, the negative impact of nonforeclosed vacancies is smaller and limited within the focal neighborhood. Other studies find a positive relationship between the presence of foreclosure-driven vacant houses and crimes (Cui and Walsh, 2015; Spader et al., 2016; Vyas, 2016).

\section{DATA}

To examine the externality of vacant single-family houses, we use two cross-sectional datasets. One dataset contains the locations and conditions of vacant houses. The other dataset contains data regarding the rent, location, and physical attributes of housing units in the rental housing market.

in Japan and the American Housing Survey in the U.S., is based on investigation from random sampling and the data are aggregated to the neighborhood level to be disclosed in public. Even if researchers have access to the individual survey data, random sampling is not sufficient to employ the level of analysis that is of interest in this study.

${ }^{12}$ Mikelbank (2008) has access to the rich data obtained from the Franklin County auditor, City of Columbus, and Community Research Partners. He states that "(t)his research would not have been possible without their cooperation. It is relatively rare to find a city with quality information across its sales, vacancies, and foreclosures. This is likely the reason that these three topics have yet to be studied together at the parcel level" (Mikelbank, 2008, p. 7). Additionally, Morckel (2014a) suggests that "it may be necessary to conduct foot surveys in order to capture the intended construct" (Morckel, 2014a, p. 122), and he reveals that different proxies of housing abandonment and vacancy can give diverse estimation results.

(c)Southern Regional Science Association 2020. 


\subsection{Vacant Housing Data}

The data on vacant houses were provided by the Toshima municipality in the Tokyo prefecture under a contractual research agreement between the municipality and the authors. The data were obtained from a large-scale field survey conducted between September 2016 and March 2017. The survey was conducted in two steps. First, the investigators visited all existing houses in the municipality and listed the potentially vacant houses based on a visual assessment. A house was categorized as a "potential vacant house" if there was no sign that someone was living there. For instance, the mailbox was filled with flyers and the electricity meter was not operating. During this step, 2,117 of 28,723 family houses were listed as "potential vacant houses." During the second step, more detailed field surveys were conducted and letters were sent to the owners of the potentially vacant houses to confirm their vacancy. Finally, after responses were received from the owners, 594 houses were determined to be "vacant houses." These vacant houses include houses whose owners did not reply, reported that the houses were unused for a long time, or had unknown owners. In addition to vacant houses, the data includes the location of apartment buildings with vacancy rates higher than 30 percent.

The vacant housing data include information regarding the physical conditions as evaluated by the investigators' visual assessments. The assessed conditions include whether the building was slanted; whether a gate, fence, wall, roof, outer wall, gutter, window shutter, balcony, nameplate, antenna, carport, or shed were damaged; whether there were any fallen objects, unattended overgrown vegetation, or combustible material such as garbage bags and stacks of waste paper; and whether a mailbox and electricity meter were present. If the visual assessment was not possible due to the presence of a high outer wall and/or the absence of an accessible road around the property, these items were reported as "unknown." Unfortunately, the survey did not record whether a gate, fence, wall, etc., exists, and therefore, the classification is likely to be "unknown" even when an object, such as a gate or a fence, is not present on the property, confounding the interpretation of the estimation results. Accordingly, we selected conditions of damage to objects that should exist in any house, namely, the walls, roof, gutters and windows, for the empirical analysis. Table 1 describes the number of vacant houses by condition.

\subsection{Rental Housing Data}

Rental housing data were obtained from a website of the Home's real estate agency (https: //www.homes.co.jp/). The detailed addresses, various housing attributes and registered rents for 4,132 listed properties in the Toshima municipality were extracted from the website in July 2017. The information regarding the housing attributes includes the floor level, floor area, number of bedrooms, walking time to the closest rail station, age of the building, type of building, type of structure and the existence of various amenities, such as a balcony, security camera, air conditioner, etc. These attributes are used as control variables in the hedonic function introduced in the following section. The rental housing samples with missing values and outlying values of continuous variables above the $99^{\text {th }}$ percentile and below the first percentile are excluded, resulting in a dataset of 3,806 observations for the empirical

(C)Southern Regional Science Association 2020. 
Table 1: Conditions of the Vacant Houses (594 Vacant Houses)

\begin{tabular}{llc}
\hline \hline Variables used in the estimations of Models 4 & Obs. \\
\hline Lean & $1=$ building slants & 22 \\
Lean_ukn & $1=$ condition of the building slant is unknown & 90 \\
& All walls of the building stand vertically & 482 \\
Wall & $1=$ wall is damaged & 3 \\
Wall_ukn & $1=$ condition of the wall is unknown & 430 \\
& Wall is not damaged & 161 \\
Roof & $1=$ roof is damaged & 12 \\
Roof_ukn & $1=$ condition of the roof is unknown & 465 \\
& Roof is not damaged & 117 \\
Gutter & $1=$ gutter is damaged & 44 \\
Gutter_ukn & $1=$ condition of the gutter is unknown & 178 \\
& Gutter is not damaged or does not exist & 372 \\
Window & $1=$ window is damaged & 41 \\
Window_ukn & $1=$ condition of the windows is unknown & 150 \\
& No windows are damaged & 403 \\
Other & $1=$ there is damage on the property other than the damage listed above \\
Other_ukn & $1=$ condition of the property other than the factors above is unknown & 105 \\
& There is no damage to the property other than that listed above & 146 \\
FallenObj & $1=$ fallen object is present & 343 \\
FallenObj_ukn & $1=$ presence of a fallen object is uncertain & 15 \\
& No fallen object is present & 198 \\
OvergrownVegetation & $1=$ tree and/or plant overgrowth (*a) & 381 \\
OvergrownVegetation_ukn & $1=$ presence of overgrown tree or plant is uncertain \\
& Overgrown tree or plant not present & 89 \\
CombustibleObj & $1=$ combustible object present (*b) & 77 \\
CombustibleObj_ukn & $1=$ presence of a combustible object is uncertain & 428 \\
& Combustible object not present & 93 \\
\hline
\end{tabular}

The survey assessed the conditions of vacant houses to determine whether there was any damage to a gate, fence, wall, roof, outer wall, gutter, window shutter, balcony, nameplate, antenna, carport, or shed and to determine the presence of fallen objects, exuberating trees and branches, combustible materials, a mailbox, and an electricity meter. Unfortunately, the survey did not record the presence of a gate, fence, wall, etc., and therefore, the classification is likely to be "unknown" even if an object, such as a gate or a fence, was not present. This confounds the interpretation of the estimation results. Accordingly, we use variables representing damage only to objects that should exist in any house, namely, the walls, roof, gutters, and windows, in the empirical estimation. (*a) Investigators were asked to choose either one of "normal," "overgrown," or "unknown" as a response to a question "Is there any tree?" (*b) Wooden furniture and garbage bags seem to be the main types of combustible objects according to pictures of houses classified in the category.

analysis. $^{13}$

By using the addresses of housing properties in both datasets of vacant houses and rental housing units, we construct variables representing the proximity to (or intensity of) neighboring vacant houses and apartment buildings with high vacancy rates.

Figure 2 shows the geographic distribution of the sample of rental housing units. A darker plot indicates a rental housing unit with a greater number of nearby vacant houses. The areas enclosed by solid lines are the 81 districts in Toshima municipality whose unobservable fixed effects will be controlled for in the estimation. The basic statistics and definitions of the variables used in the following analysis are described in Table 2.

${ }^{13}$ The inclusion of outliers does not alter the implications of the results but gives even more robust results in terms of statistical significance and magnitudes of coefficients of the variables of interest. 


\section{Figure 2: Tokyo Prefecture (on the Left) and the Distribution of Rental Housing Units in the Toshima Municipality (on the Right)}

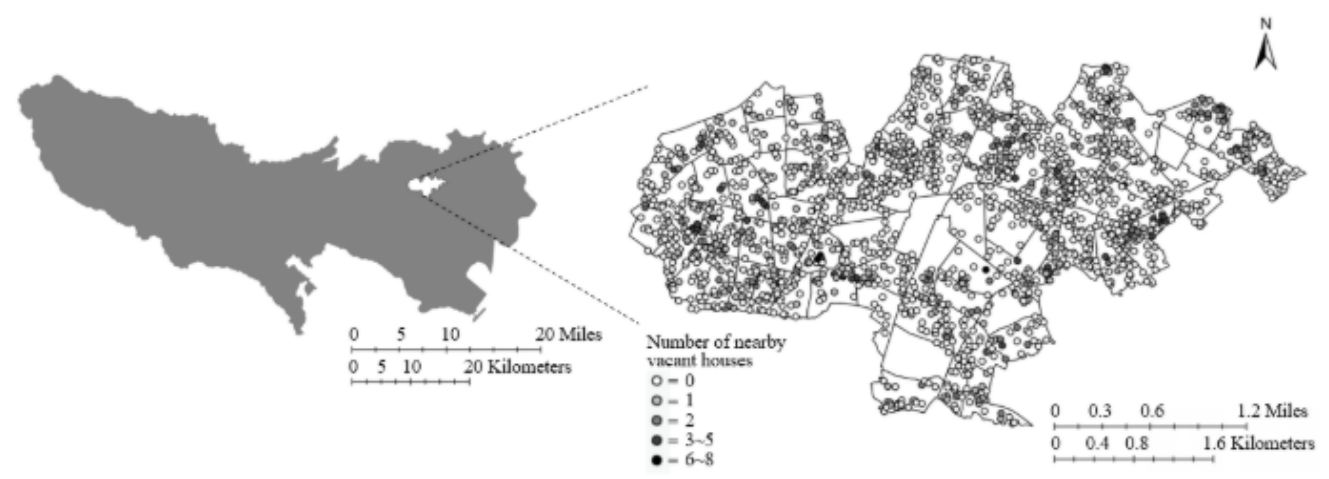

The map on the right shows the geographic distribution of the rental housing unit sample used in the regression analysis and the number of vacant houses within $50 \mathrm{~m}$ (0.031 mile). Darker colors indicate a greater number of nearby vacant houses in the sample. Empty areas without any rental housing units represent a large rail station (Ikebukuro station), universities (Gakusyuin Women's College, Tokyo College of Music, and Rikkyo University) and cemeteries (Zoshigaya cemetery and Somei cemetery).

\section{EMPIRICAL MODEL}

We estimate the following hedonic housing-rental-price function to examine the externality of vacant houses:

$$
\ln \left(\text { Rent }_{i}\right)=V H_{i} \alpha+X_{i} \beta+\epsilon_{i}
$$

where the dependent variable $\ln \left(\right.$ Rent $\left._{i}\right)$ is a logarithmic value of the monthly listed rent of rental housing unit $i ; V H_{i}$ is a row vector of variables indicating the proximity to (or intensity of) vacant houses surrounding rental housing unit $i ; \alpha$ is a column vector of the parameters associated with $V H_{i} ; X_{i}$ is a row vector of the variables of housing $i$ 's attributes and neighborhood characteristics; $\beta$ is a column vector of the parameters associated with $X_{i}$; and $\epsilon_{i}$ is an error term. ${ }^{14}$

The primary limitation of this research as well as other related studies that utilize parcel-level data to examine the impact of vacant and dilapidated houses (Mikelbank, 2008; Whitaker and Fitzpatrick IV, 2013; Awazu, 2014; Paredes and Skidmore, 2017) is that the research is based on cross-sectional data due to the difficulty of constructing panel data on vacancy status, as noted above. A negative correlation between the rental price and the presence of nearby vacant houses may reflect not only the externality of vacant houses but also the fact that a house is more likely to be abandoned and become vacant in areas where

\footnotetext{
${ }^{14}$ Because we do not observe vacant houses outside Toshima municipality, the externality may be underestimated near the boundary of the municipality, which is known as a boundary effect. To address the boundary effect, cross-terms between the proximity variables of nearby vacant houses, i.e., $V H_{i}$, and dummy variables indicating rental housing samples located within $50 \mathrm{~m}$ and $50-100 \mathrm{~m}$ from the boundary are included as control variables in addition to the control variables listed in Table 2.
} 
Table 2: Basic Statistics for the Rental Housing Sample

\begin{tabular}{|c|c|c|c|c|c|}
\hline Variables & Definition & Mean & S.D. & Min & $\operatorname{Max}$ \\
\hline Rent & $\begin{array}{l}\text { Monthly listed rental price in } 10,000 \text { yen } \\
\text { (91 US dollars with an assumed exchange rate of } 110 \text { yen to the dollar) }\end{array}$ & 9.27 & 3.28 & 4.5 & 24.9 \\
\hline \multicolumn{6}{|c|}{ Proximity variables to vacant single-family houses } \\
\hline DistVH & Distance to the closest vacant house in $1,000 \mathrm{~m}$ & 0.10 & 0.06 & 0.01 & 0.32 \\
\hline cVH50 & Number of vacant houses within $50 \mathrm{~m}$ (0.031 mile) & 0.31 & 0.62 & 0 & 3 \\
\hline$c V H 100$ & Number of vacant houses between 50 and $100 \mathrm{~m}$ (0.031-0.062 mile) & 0.99 & 1.36 & 0 & 7 \\
\hline$d V H 50$ & $1=$ closest vacant house within $50 \mathrm{~m} ; 0=$ o.w. & 0.25 & 0.43 & 0 & 1 \\
\hline$d V H 100$ & $1=$ closest vacant house between 50 and $100 \mathrm{~m} ; 0=$ o.w. & 0.34 & 0.47 & 0 & 1 \\
\hline$d V H 50 \_2$ & $1=$ second closest vacant house within $50 \mathrm{~m} ; 0=\mathrm{o} . \mathrm{w}$ & 0.07 & 0.25 & 0 & 1 \\
\hline$d V H 100 \_2$ & $1=$ second closest vacant house between 50 and $100 \mathrm{~m} ; 0=$ o.w. & 0.28 & 0.45 & 0 & 1 \\
\hline \multicolumn{6}{|c|}{ Proximity variables to apartment buildings with high vacancy rates } \\
\hline$c V A 50$ & Number of apartments with vacant units $>30 \%$ within $50 \mathrm{~m}$ & 0.31 & 0.55 & 0 & 2 \\
\hline$c V A 100$ & Number of apartments with vacant units $>30 \%$ between 50 and $100 \mathrm{~m}$ & 0.93 & 1.05 & 0 & 4 \\
\hline$d V A 50$ & $1=$ closest apartment with vacant units $>30 \%$ within $50 \mathrm{~m} ; 0=$ o.w. & 0.27 & 0.45 & 0 & 1 \\
\hline $\begin{array}{l}d V A 100 \\
\text { Other variables }\end{array}$ & \multicolumn{4}{|l|}{ 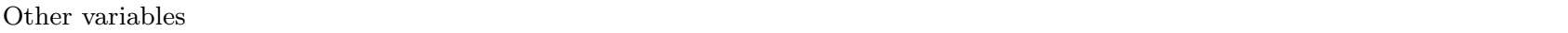 } & 1 \\
\hline FLevel & Floor level & 3.66 & 2.90 & 1 & 16 \\
\hline FArea & Floor space (square meters) & 27.6 & 11.5 & 10.0 & 76.1 \\
\hline Bedrooms & Number of bedrooms & 1.16 & 0.41 & 1 & 3 \\
\hline Age & Age of the building (months) & 249 & 161 & 2 & 632 \\
\hline Underground & $1=$ unit located underground; $0=\mathrm{o} . \mathrm{w}$ & 0.02 & 0.13 & 0 & 1 \\
\hline New & $1=$ no one ever lived in the unit; $0=$ o.w. & 0.08 & 0.26 & 0 & 1 \\
\hline FL1 & $1=$ unit located on the first floor of a building; $0=\mathrm{o} w$ & 0.19 & 0.39 & 0 & 1 \\
\hline South & $1=\mathrm{a}$ window faces south; $0=\mathrm{o} . \mathrm{w}$ & 0.23 & 0.42 & 0 & 1 \\
\hline Park & $1=$ parking lot available $; 0=$ o.w. & 0.08 & 0.27 & 0 & 1 \\
\hline AutoLock & $1=$ building entrance with an autolock system; $0=$ o.w. & 0.53 & 0.50 & 0 & 1 \\
\hline$A C$ & $1=$ air conditioner equipped $0=\mathrm{o} . \mathrm{w}$ & 0.96 & 0.19 & 0 & 1 \\
\hline UnitBath & $1=$ bath and toilet in separate rooms; $0=$ o.w. & 0.71 & 0.45 & 0 & 1 \\
\hline AutoBath & $1=$ automatic bath water boiling system equipped; $0=$ o.w. & 0.22 & 0.41 & 0 & 1 \\
\hline Flooring & $1=$ wooden floor; $0=$ floor is made of other materials & 0.78 & 0.42 & 0 & 1 \\
\hline Pet & $1=$ pet is allowed; $0=0 . w$ & 0.10 & 0.30 & 0 & 1 \\
\hline Available & $1=$ unit is available for rent immediately; $0=0 . w$ & 0.76 & 0.43 & 0 & 1 \\
\hline Insurance & $1=$ required to buy residential insurance; $0=$ o.w. & 0.98 & 0.15 & 0 & 1 \\
\hline SecurityCam & $1=$ security camera system; $0=0 . w$ & 0.26 & 0.44 & 0 & 1 \\
\hline CityGas & $1=$ gas provided by city gas; $0=0 . w$. & 0.86 & 0.35 & 0 & 1 \\
\hline Apartment 2 & $1=$ luxury apartment; $0=$ o.w. & 0.80 & 0.40 & 0 & 1 \\
\hline Box & $1=$ apartment with parcel lockers; $0=$ o.w & 0.30 & 0.46 & 0 & 1 \\
\hline DistStation & Walking time to the closest station & 6.24 & 3.33 & 1 & 15 \\
\hline \multicolumn{6}{|l|}{ Categorical } \\
\hline Structure $_{s}$ & $1=$ building structure is $s$ (reinforced concrete, wooden, etc.); $0=$ o.w. & & & & \\
\hline Transportation $_{l}$ & $1=$ train $/$ subway line $l$ at the closest station; $0=$ o.w. & & & & \\
\hline LandU $_{\mathrm{u}}$ & $1=$ land-use classification is $u$ (residential, commercial, etc.); $0=$ o.w. & & & & \\
\hline District $_{d}$ & $1=$ unit located in district $\mathrm{D} ; 0=\mathrm{o} . \mathrm{w}$ & & & & \\
\hline
\end{tabular}

the average rent is relatively low. Controlling for the latter effect to identify the former effect based on cross-sectional data is challenging. We acknowledge that there are some potential omitted variables that may influence rental prices. For instance, information about the spatial distribution of vacant lots and occupied dilapidated properties is missing, while it is likely to have some negative impact on nearby property values (Paredes and Skidmore, 2017). When vacant lots, occupied dilapidated properties, and vacant houses tend to cluster in the same area, the model can overestimate the externality of vacant houses if no adequate treatment to the regression model is made.

To address potential endogeneity problems to some extent, this research introduces unique control variables that have not been considered in previous studies, namely, (i) detailed district dummy variables, (ii) categorical dummy variables representing land-use classifications, and (iii) proximities to nearby apartment buildings with vacancy rates higher than 30 per- 
cent. The district dummy variables can address the unobservable district-specific effect in each district within an area of approximately 160,000 square meters (i.e., 0.062 square miles) on average. None of the previous studies considers such detailed regional fixed effects in estimations. There are 13 land use classifications for residential, commercial, and industrial areas, such as floor-area ratio, building-to-land ratio and property purpose, that building regulations are based on. Such zoning can have a significant influence on the distribution of vacant houses, as it regulates the flexibility of redevelopment. A high vacancy rate in an apartment building implies an unattractiveness of the area surrounding the apartment or the fact that the owner does not properly maintain the building, which may cause a negative externality. Although we cannot distinguish between these two factors, the variable helps us to capture local unobservable effects that cannot be addressed by using only district dummy variables.

While we acknowledge that potential endogeneity cannot be fully addressed, our unique data and approaches provide strong evidence regarding the externalities of vacant houses. Our analaysis will enable local authorities to make more informed decisions and provide a useful reference to researchers who will investigate similar issues in the future.

We estimate four hedonic functions using different sets of $V H_{i}$ as follows.

$$
V H_{i}^{1} \alpha^{1}=\alpha_{50}^{1} d V H_{i}^{50}+\alpha_{100}^{1} d V H_{i}^{100}
$$

In Model 1 , the dummy variables $d V H_{i}^{50}$ and $d V H_{i}^{100}$ take values of one if rental housing $i$ from which the closest vacant house is located within $50 \mathrm{~m}$ and within $50-100 \mathrm{~m}$, respectively. The parameter $\alpha_{50}^{1}\left(\alpha_{100}^{1}\right)$ implies a difference in the rental price between a rental housing unit from which the closest vacant house is located within $50 \mathrm{~m}$ (between 50 and 100m) and a rental housing unit from which the closest vacant house is located farther than $100 \mathrm{~m}$ away. Because the impact of an externality diminishes with distance, we expect that $\alpha_{50}^{1}<\alpha_{100}^{1}<0$ if a vacant house has a significant negative impact on a neighboring dwelling environment.

$$
V H_{i}^{2} \alpha^{2}=\alpha_{50}^{2} d V H_{i}^{50(2)}+\alpha_{100}^{2} d V H_{i}^{100(2)}+\alpha_{D i s t}^{2} \text { Dist } V H_{i}
$$

In Model 2, the Euclidian distance of $1,000 \mathrm{~m}$ to the closest vacant house, DistV $H_{i}$, is introduced to examine the marginal effect of the distance to the closest vacant house. Therefore, the dummy variables are adjusted to $d V H_{i}^{50(2)}$ and $d V H_{i}^{100(2)}$, which take values of one if rental housing $i$ from which the second closest house is within $50 \mathrm{~m}$ and within $50-100 \mathrm{~m}$, respectively. The parameter $\alpha_{\text {Dist }}^{2}$ indicates the change in the rental price as the distance to the closest vacant house increases by $1,000 \mathrm{~m}$. If the negative impact of the closest vacant house decreases with distance, $\alpha_{\text {Dist }}^{2}$ takes on a positive sign.

$$
V H_{i}^{3} \alpha^{3}=\alpha_{50}^{3} c V H_{i}^{50}+\alpha_{100}^{3} c V H_{i}^{100}
$$

In Model 3, instead of using dummy variables, the counts of vacant houses within 50m and within 50-100m, i.e., $c V H_{i}^{50}$ and $c V H_{i}^{100}$, respectively, are used to examine the relationship between the geographic intensity of vacant houses and nearby rental prices. Here, $\alpha_{50}^{3}\left(\alpha_{100}^{3}\right)$ implies the change in the rental price by an additional vacant house within $50 \mathrm{~m}$ (within 50-100m).

(C)Southern Regional Science Association 2020. 


$$
\begin{array}{r}
V H_{i}^{4} \alpha_{(j)}^{4}=\alpha_{50(j)}^{4} d V H_{i(j)}^{50}+\alpha_{100(j)}^{4} d V H_{i(j)}^{100}+\gamma_{50(j)}^{4} d V H_{-} u n k_{i(j)}^{50}+ \\
\gamma_{100(j)}^{4} d V H_{-} u n k_{i(j)}^{100}+\rho_{50(-j)}^{4} d V H_{i(-j)}^{50}+\rho_{100(-j)}^{4} d V H_{i(-j)}^{100}
\end{array}
$$

The last model intends to investigate the heterogeneous impacts of a neighboring vacant house depending on its physical condition. Among the various conditions of vacant houses recorded in the survey, we selected the conditions of damage to the wall, roof, gutter, and window and the existence of fallen objects, combustible material, overgrown vegetation, and a building slant as factors to be examined in the analysis. If the investigators were unable to assess each condition using a visual assessment, the status was marked as "unknown." As seen in Table 2, the number of vacant houses with "unknown" status is quite large for most conditions because many houses in this study area are surrounded by a high wall and/or they do not have an accessible adjacent road, preventing the investigators from assessing the conditions. Examining the impact of the "unknown" condition is important because the uncertainty of the condition of vacant houses can affect neighboring residents' and prospective renters' perceptions of the dwelling environment and risks.

In this model, we are interested in the coefficients of four dummy variables, namely, $d V H_{i(j)}^{50}, d V H_{i(j)}^{100}, d V H_{-} u n k_{i(j)}^{50}$, and $d V H_{-} u n k_{i(j)}^{100}$. The first two variables, i.e., $d V H_{i(j)}^{50}$ and $d V H_{i(j)}^{100}$, take values of one if rental housing $i$ from which the closest vacant house with condition $j$ is located within $50 \mathrm{~m}$ and $50-100 \mathrm{~m}$, respectively. The following two variables, i.e., $d V H_{i(j)}^{50}$ and $d V H_{i(j)}^{100}$, take values of one if rental housing $i$ from which the closest vacant house with an "unknown" status regarding condition $j$ is located within $50 \mathrm{~m}$ and $50-100 \mathrm{~m}$, respectively.

To capture the effect of the presence of other vacant houses without any issues or uncertainties regarding condition $j$, the latter two dummy variables, i.e., $d V H_{i(-j)}^{50}$ and $d V H_{i(-j)}^{100}$, are included as control variables, which take values of one if rental housing $i$ from which the closest vacant house without condition $j$ is located within $50 \mathrm{~m}$ and $50-100 \mathrm{~m}$, respectively. Given the eight types of physical conditions, we performed eight separate regression analyses to examine how each type of vacant house influences nearby rental prices. ${ }^{15}$ The parameters suggest magnitudes of potential benefit (or recovery of rental price) if nearby vacant houses with particular conditions are removed, replaced with new houses, or reused as standard nonvacant houses. ${ }^{16}$

\footnotetext{
${ }^{15}$ If one attempts to assess the individual impact of each physical condition itself on nearby rental prices, all physical conditions should be used as explanatory variables in a single regression. When we estimate such a model, however, none of the conditions show any significance, which may be partly attributable to the multicollinearity issue and partly to the fact that each physical condition itself does not have a significant impact. In our study, instead of examining the individual impact of each condition, we are interested in identifying the type of vacant houses that the local authority should address given the limited public financing and human resources. The separate regressions provide more straightforward and practical implications for policy makers by suggesting specific types of vacant houses to be addressed on a priority basis.

${ }^{16}$ To provide a clearer understanding of the model, consider the example of the existence of combustible material. The variable $d V H_{i(\text { Combustible })}^{50}$ takes a value of one if the closest vacant house in which combustible material is found is within $50 \mathrm{~m}$; otherwise, its value is zero. The variable $d V H_{-} u n k_{i(\text { Combustible })}^{50}$ takes a value of one if a vacant house is present within $50 \mathrm{~m}$ and the investigators were uncertain of the existence of combustible material; otherwise, its value is zero. The parameter $\alpha_{50 \text { (Combustible) }}^{4}$ indicates the difference
} 


\section{ESTIMATION RESULTS}

First, in Table 3, we show the estimation results of Models 1, 2, and 3. The top panel of the table presents the different types of proximity variables for the neighboring vacant houses and apartments with high vacancy rates used in the models. The estimated coefficients of the proximity variables are shown in the middle panel, along with White's robust standard errors, which are shown in parentheses. The coefficients of the other variables are shown in Table A1 in Appendix 1.

In Model 1 , the coefficients of $d V H_{i}^{50}$ and $d V H_{i}^{100}$ are -0.017 and -0.009 , respectively, and they are statistically significant. Thus, if the closest vacant house is located within $50 \mathrm{~m}$ $(50-100 \mathrm{~m})$, the rental price is 1.7 percent $(0.9$ percent) lower than the price when the closest vacant house is located farther than $100 \mathrm{~m}$ (i.e., 0.062 mile) away. The coefficient of $d V A_{i}^{50}$ is negative and statistically significant as well, indicating that the presence of an apartment building with a high vacancy rate is associated with a low rental price in the area.

In Model 2, the coefficient of DistV $H_{i}$ is 0.074 and is statistically significant. Thus, the rental price appreciates by approximately 0.7 percent when the distance to the closest vacant house increases by $100 \mathrm{~m}$. This result further reveals that the presence of a second vacant house within $50 \mathrm{~m}$ negatively influences the rental price.

In Model 3, the coefficients of $c V H_{i}^{50}$ and $c V H_{i}^{100}$ are -0.007 and -0.002 , respectively, and both are statistically significant, indicating that each additional vacant house within $50 \mathrm{~m}$ (within $50-100 \mathrm{~m}$ ) lowers the rental price by 0.7 percent ( 0.2 perrcent). The negative sign of $c V A_{i}^{50}$ indicates that a cluster of apartments with many empty units is associated with a low rental price in the neighborhood.

In addition, we estimate these three models by using vacant house variables with smaller distance bins, namely, 0-25m, 25-50m, 50-75m and 75-100m, as a robustness check (Table A2 in Appendix 1). We find that the negative impact is most significant to dwellings in close proximity $(0-25 \mathrm{~m})$ and that the externality tends to decrease with distance. These results confirm that vacant houses cause negative spatial externalities by decreasing the quality of the dwelling environment in the neighborhood.

The estimation results also suggest that the presence of an apartment building with a high vacancy rate is negatively correlated with nearby rental prices. The latter observation implies the following two possibilities: (i) the owner of such an apartment building is reluctant to maintain the property to attract new tenants such that it causes the same type of negative externality as vacant houses, or (ii) the presence of an apartment building with a high vacancy rate may reflect the fact that the surrounding area is not attractive for some reason.

between the rental price due to the presence of a vacant house with combustible material within $50 \mathrm{~m}$ and the rental price when there is no vacant house within $100 \mathrm{~m}$ with any combustible material or when the

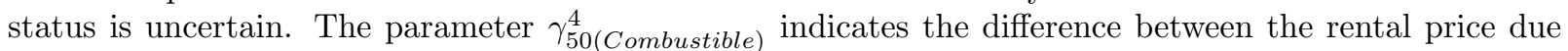
to the presence of a vacant house with uncertainty regarding the existence of combustible material within $50 \mathrm{~m}$ and the rental price when there is no vacant house within $100 \mathrm{~m}$ with any combustible material or the status is uncertain. The variables and parameters within the $50-100 \mathrm{~m}$ radius can be interpreted similarly. To control for the effect of the presence of other vacant houses without any combustible material in the neighborhood, dummy variables representing the presence of such vacant houses, i.e., $d V H_{i(-C o m b u s t i b l e)}^{50}$

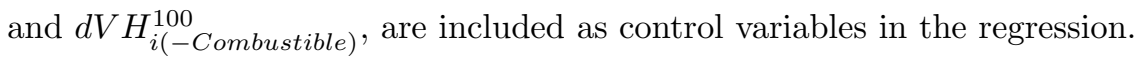

(c) Southern Regional Science Association 2020. 
Table 3: Estimation Results of Models 1, 2, and 3

\begin{tabular}{lccc}
\hline \hline & Model 1 & Model 2 & Model 3 \\
\hline \multirow{4}{*}{ VH50 } & Variables for neighboring vacant houses and high vacancy rate apartments \\
VH100 & $d V H 50$ & $d V H 50(2)$ & $c V H 50$ \\
VA50 & $d V H 100$ & $d V H 100(2)$ & $c V H 100$ \\
VA100 & $d V A 50$ & $d V A 50$ & $c V A 50$ \\
\hline \multirow{4}{*}{ VH50 } & $d V A 100$ & $d V A 100$ & $c V A 100$ \\
& Variables for neighboring vacant houses \\
VH100 & $-0.017^{* * *}$ & $-0.016^{* *}$ & $-0.007^{* *}$ \\
& $(0.005)$ & $(0.007)$ & $(0.003)$ \\
DistVH & $-0.009^{*}$ & -0.000 & $-0.002^{*}$ \\
& $(0.004)$ & $(0.005)$ & $(0.001)$ \\
& & $0.074^{*}$ & \\
VA50 & & $(0.004)$ & \\
& & $-0.011^{* *}$ & $-0.009^{* * *}$ \\
VA100 & $-0.012^{* *}$ & $(0.005)$ & $(0.003)$ \\
& $(0.005)$ & -0.004 & 0.001 \\
& -0.005 & $(0.004)$ & $(0.002)$ \\
\hline Observations & $(0.004)$ & 3728 & 3691 \\
$R^{2}$ & 3806 & 0.9217 & 0.9210 \\
\hline \hline
\end{tabular}

The dependent variable is the logarithmic value of the monthly rental price of a rental housing unit. ${ }^{* *},{ }^{* *}$, and $*$ indicate 1 percent, 5 percent, and 10 percent significance levels, respectively. White's robust standard errors are shown in parentheses. The results of the control variables are not shown in the table. $d V H$ and $c V H$ indicate a dummy variable and a count of neighboring vacant house(s), and $d V A$ and $c V A$ indicate those of neighboring apartment buildings with vacancy rates higher than 30 percent, respectively. Dummy variables $d V H 50$ and $d V H 100$ indicate a rental housing unit with at least one vacant house within 0-50 $\mathrm{m}$ and 50-100 m, respectively. Dummy variables $d V H 50(2)$ and $d V H 100(2)$ indicate a rental housing unit with at least one vacant house in addition to the closest vacant house within $0-50 \mathrm{~m}$ and 50-100 m, respectively. DistVH is the distance to the closest vacant house.

Although we cannot estimate these two effects separately, the proximity variables of the apartment buildings along with the district dummy variables and land use classification dummy variables enable us to extract a more precise impact of vacant houses by controlling for complex unobserved local area specific effects.

In Table 4, we show the results of Model 4. The first two columns, i.e., [4-1] and [42 ], show the estimated coefficient significance levels. The results are obtained from eight separate regression analyses, each of which uses four proximity variables for each condition $j$. The three columns on the right are estimates of the extra property tax revenues in cases in which vacant houses with particular conditions are addressed. We first explain the results of the coefficients and then discuss the tax revenues.

Regarding the coefficients of $d V H_{i(j)}^{50}$ and $d V H_{i(j)} 100$, the results show that vacant houses entail a negative externality if the building is slanted; there is damage to a wall, roof or window; there is a fallen object or combustible material; and the house has exuberating branches. ${ }^{17}$ Although the results are not statistically significant due to the small number

\footnotetext{
${ }^{17}$ Although the externality is expected to be more significant at a closer distance, the results do not show
} 
Table 4: Estimation Results of Model 4 and Additional Property Tax Income

\begin{tabular}{|c|c|c|c|c|c|c|}
\hline & \multicolumn{2}{|c|}{ Model 4} & \multicolumn{4}{|c|}{$\begin{array}{l}\text { Estimates of increase in property tax income } \\
\text { (in } 1,000 \text { yen) }\end{array}$} \\
\hline & \multirow{3}{*}{$\begin{array}{c}\text { dVH50(j) } \\
\text { dVH_ukn50(j) }\end{array}$} & \multirow{3}{*}{$\begin{array}{c}\begin{array}{c}\mathrm{dVH} 100(\mathrm{j}) \\
\mathrm{dVH} \_\mathrm{knn} 100(\mathrm{j})\end{array} \\
{[4-2]}\end{array}$} & \multirow{3}{*}{$\begin{array}{c}\text { Total } \\
\begin{array}{c}\text { Point } \\
\text { estimates }\end{array} \\
{[4-3]}\end{array}$} & & \multicolumn{2}{|c|}{ Per vacant house } \\
\hline & & & & $\begin{array}{c}\text { Point } \\
\text { estimates }\end{array}$ & $\begin{array}{l}95 \% \mathrm{cc} \\
{[\text { lower/ }}\end{array}$ & $\begin{array}{l}\text { interval } \\
\text { higher } / \mathrm{b}]\end{array}$ \\
\hline & & & & {$[4-4]$} & & $-5]$ \\
\hline \multicolumn{7}{|l|}{ Estimations } \\
\hline Lean & 0.006 & $-0.021^{* *}$ & $-9,983$ & -454 & $-3,074$ & 2,167 \\
\hline Lean_ukn & $-0.035^{* * *}$ & $-0.013^{* *}$ & $120,139 * * *$ & 1,335 & 650 & 2,019 \\
\hline Wall & -0.073 & $-0.036^{*}$ & 19,661 & 6,554 & $-6,479$ & 19,586 \\
\hline Wall_ukn & $-0.014^{* * *}$ & $-0.008^{*}$ & $215,282^{* * *}$ & 501 & 192 & 809 \\
\hline Roof & -0.006 & $-0.028^{* *}$ & 8,519 & 710 & -133 & 2,746 \\
\hline Roof_ukn & $-0.017^{* * *}$ & $-0.011^{* * *}$ & $299,948^{* * *}$ & 645 & 342 & 948 \\
\hline Gutter & -0.007 & -0.006 & 18,647 & 424 & -416 & 1,264 \\
\hline Gutter_ukn & $-0.015^{* * *}$ & -0.004 & $83,408^{* *}$ & 469 & 47 & 890 \\
\hline Window & $-0.021^{*}$ & -0.001 & 19,808 & 483 & -428 & 1,394 \\
\hline Window_ukn & -0.010 & -0.006 & $65,087^{*}$ & 434 & -451 & 318 \\
\hline FallenObj & -0.015 & $-0.019^{*}$ & 15,831 & 1,055 & -445 & 2,555 \\
\hline FallenObj_ukn & $-0.011^{*}$ & 0.003 & 10,755 & 54 & -403 & 512 \\
\hline OvergrownVegetation & $-0.019 * *$ & -0.006 & $91,543^{* *}$ & 1,029 & 156 & 1,901 \\
\hline OvergrownVegetation_ukn & $-0.015^{*}$ & $0.010^{*}$ & $-17,345$ & -225 & -960 & 509 \\
\hline CombustibleObj & $-0.022^{* *}$ & $-0.020^{* * *}$ & $124,005^{* * *}$ & 1,333 & 672 & 1,995 \\
\hline CombustibleObj_ukn & $-0.017^{* *}$ & 0.004 & $190,770^{*}$ & 1,255 & -11 & 2,521 \\
\hline
\end{tabular}

***, **, and * indicate significance at the 1 percent, 5 percent, and 10 percent levels, respectively. Confidence intervals and significance levels of the estimates of the increases in property tax income are computed based on the delta method.

of vacant houses with damage to a wall within $50 \mathrm{~m}$, there may be a substantial negative impact on nearby rental prices in terms of the magnitude of the coefficient. Vacant houses with combustible materials present and exuberating trees/branches also have relatively large impacts on nearby rental prices.

Interestingly, we observe that some coefficients of $d V H_{-} u n k_{i(j)}^{50}$ and $d V H_{-} u k n_{i(j)}^{100}$ have negative and significant signs. These results imply that a negative externality exists when there is some uncertainty about the condition of a property. In particular, uncertainty about slanted buildings has a significant negative impact. We assume that the vacant houses assigned an "unknown" status are protected by a high outer wall or trees, thus giving neighbors an uneasy feeling about the safety of the dwelling.

Using the results of Model 4, the potential increase in the property tax income in the Toshima municipality from addressing vacant houses with a specific condition can be calculated. Appendix 2 describes the detailed procedure of the calculation. In brief, the effect of addressing vacant houses on the property prices in the neighborhood is calculated, under several assumptions, by multiplying estimated property tax income within 100m from

significant signs of a negative externality within $50 \mathrm{~m}$ in terms of damage to a wall or roof or the presence of a fallen object. However, the signs become significant at 50-100m. There are two possible explanations for these results. First, the number of observations of rental housing within $50 \mathrm{~m}$ of vacant houses with these conditions is not high enough to produce significant results. For instance, only three and 12 of a total of 594 vacant houses have damage to a wall and the roof, respectively, as shown in Table 1. Second, the area with a vacant house that has a particular condition is likely to also have nonvacant housing with the same condition. Such endogeneity represents a type of peer effect; for instance, people think that it is acceptable to not fix a damaged roof because their neighbors also do not fix their roofs, and thus, the neighborhood quality decreases. Panel data and more sophisticated estimation strategies are needed to test these possibilities. 
targeted vacant houses by the estimates of the externality.

The three columns from [4-3] to [4-5] show the point estimates of the total tax increases, the tax increase per vacant house with condition $j$, and the 95 percent significance intervals, respectively. Considering the estimates of the total tax increase, addressing vacant houses with uncertainty regarding the condition of the roof could generate the greatest increase in property tax income (approximately 300 million yen or 27 thousand dollars). However, because the number of vacant houses with an "unknown" status regarding the roof, i.e., 465 of 594, is high, addressing all these vacant houses could be costly. From a cost-benefit perspective, the number of vacant houses with each of the different conditions needs to be considered to evaluate the benefit of targeting a particular type of vacant house.

Column [4-4] shows the point estimates per vacant house (i.e., the total increase in property tax income divided by the number of vacant houses with a particular condition). The results indicate that addressing the three vacant houses with damage to the walls could be the most efficient based on a cost-benefit analysis, although the statistical confidence level is weak. If the demolition cost per house is two million yen (approximately 18 thousand dollars) on average, removing all three vacant houses using public financing could yield a net financial benefit of approximately four million yen (36 thousand dollars) in one year.

However, we should note two limitations when interpreting the results. First, the significance intervals must be assessed. Because of the small number of vacant houses with damaged walls, the standard deviation of the estimate is very large and evaluating the benefit by considering only the point estimate is not convincing. Addressing vacant houses with overgrown vegetation, combustible materials, or uncertainty regarding the building slant could produce annual tax gains greater than one million yen per vacant house with a high probability. Furthermore, as noted above, the cost associated with addressing vacant houses not only includes the cost of demolition and rehabilitation but also involves difficult and time-consuming communications and arrangements with stakeholders.

Nevertheless, local governments should recognize the potential benefits of addressing different types of vacant houses to make better decisions regarding countermeasures. The procedures used to address poorly managed vacant houses, i.e., removing a house, replacing a house with a new house, or using an existing house for a different purpose, requires considerable costs in terms of money and time, including identifying the owner, communicating with all stakeholders to determine how to address the house, and finding a new tenant, owner, or someone else who can utilize the vacant house. Given the limited public financing that can be used to address the vacant house issue, it is helpful for local authorities to discern types of vacant houses that have significant negative impacts on the neighboring dwelling environment to implement effective measures by focusing on these particularly problematic houses.

\section{CONCLUSION}

We estimated the negative externalities associated with vacant single-family houses in the Toshima municipality in Tokyo, Japan, using a hedonic approach with data on 594 vacant houses and 3,806 rental housing units. On average, the estimation results reveal that having

(c)Southern Regional Science Association 2020. 
a vacant house within $50 \mathrm{~m}$ (0.031 mile) and 50-100m (0.031-0.062 mile) reduces a rental unit's price by 1.7 percent and 0.9 percent, respectively. Having one additional vacant house within $50 \mathrm{~m}$ and $50-100 \mathrm{~m}$ is associated with 0.7 percent and 0.2 percent reductions in nearby rental prices, respectively. Confounding neighborhood-specific effects are addressed by introducing very fine district dummy variables, categorical dummy variables representing land use classifications and proximity variables of nearby apartment buildings with high vacancy rates. ${ }^{18}$ A robustness check using finer distance categories for vacant house variables confirms that a vacant house has the greatest influence on the closest property and that the externality tends to decrease with distance (Table A2 in Appendix 1).

Furthermore, vacant houses with combustible materials on the property, damaged walls, and uncertainty regarding the presence of a slanted building are found to have high negative externalities. By focusing on addressing vacant houses with combustible materials, for instance, the local government of the Toshima municipality could increase its annual property tax income by approximately 120 million yen (1.1 million U.S. dollars), or 1.3 million yen $(12,000$ U.S. dollars) per vacant house. These figures are approximately the same in the case of vacant houses with uncertainty regarding whether the building is slanted. The demolition cost of such a dilapidated vacant house can be offset by extra tax gains a few years after demolition even though it may take substantial time and perseverance to reach an agreement among the various stakeholders.

The limitation of this research, as with previous related studies, is that it is based on cross-sectional data. We acknowledge that there are some potential omitted variables. For instance, information on the spatial distribution of vacant lots and occupied dilapidated properties is missing, which may have yielded an overestimation of the externality of vacant houses to some extent. While we acknowledge that endogeneity cannot be fully addressed, we believe that our unique data and approaches provide strong evidence regarding the negative externality of vacant houses.

The Japanese government has promoted the construction of new residential buildings for a long time through various policies to stimulate the economy. However, institutional reform regarding the use of the existing housing stock is necessary under the current context of the decreasing population and increasing number of vacant houses. In particular, a radical reform of the property tax system that currently favors owners of vacant houses is necessary. England has removed the property tax discount given to owners of vacant houses (Henderson, 2015). Such a tax reform can incentivize owners to demolish unused properties in Japan. A smooth ownership transfer of real estate to a new owner is also key because vacant lots may still induce a negative impact on the local housing market in the neighborhood (Paredes and Skidmore, 2017).

Although tax reform at the national level may be a lengthy procedure in Japan, more measures can be taken at the local level. In particular, the assessment of the externality of vacant houses, as in this study, can be helpful for the local government to consider efficient

\footnotetext{
${ }^{18}$ If the variables for land use classifications and detailed regional fixed effects are removed as in Awazu (2014), the estimates of the impact of the presence of vacant house in Model 1 change from 1.7 percent to 2.5 percent for a $50 \mathrm{~m}$ radius and from 0.9 percent to 1.3 percent for a $50-100 \mathrm{~m}$ radius, and the estimates of the impact of an addition vacant house in Model 3 change from 0.7 percent to 0.8 percent for a $50 \mathrm{~m}$ radius and from 0.2 percent to 0.3 percent for a $50-100 \mathrm{~m}$ radius.
}

(c)Southern Regional Science Association 2020. 
countermeasures. In future research, examinations based on complete surveys in more regions are needed for a comprehensive picture of the issues associated with vacant properties in Japan. It would also be beneficial to conduct complete surveys multiple times within the same region, allowing the difference-in-differences approach to be employed to more precisely identify the causal effects of vacant properties.

\section{REFERENCES}

Arsen, David. (1992) "Property Tax Assessment Rates and Residential Abandonment: Policy for New York City," American Journal of Economics and Sociology, 51(3), 361-377.

Awazu, Takashi. (2014) "The Study Related with the External Effect and the Effect of Countermeasures for Unmaintained Vacant Houses and Buildings," Urban Housing Sciences, 87, 209-217.

Baba, Hiroki and Kimihiro Hino. (2019) "Factors and Tendencies of Housing Abandonment: An Analysis of a Survey of Vacant Houses in Kawaguchi City, Saitama," Japan Agricultural Review, 2(3), 367-375.

Bak, Xian F. and Geoffrey J.D. Hewings. (2017) "Measuring Foreclosure Impact Mitigation: Evidence from the Neighborhood Stabilization Program in Chicago," Regional Science and Urban Economics, 63, 38-56.

Bender, Bruce. (1979) "The Determinants of Housing Demolition and Abandonment," Southern Economic Journal, 46(1), 131-144.

Boessen, Adam and Alyssa W Chamberlain. (2017) "Neighborhood Crime, the Housing Crisis, and Geographic Space: Disentangling the Consequences of Foreclosure and Vacancy," Journal of urban Affairs, 39(8), 1122-1137.

Campbell, John Y., Stefano Giglio, and Parag Pathak. (2011) "Forced Sales and House Prices," American Economic Review, 101(5), 2108-2131.

Cohen, James R. (2001) "Abondoned Housing: Exploring Lessons from Baltimore," Housing Policy Debate, 12(3).

Cui, Lin and Randall Walsh. (2015) "Foreclosure, Vacancy, and Crime," Journal of Urban Economics, 87, 72-84.

Department for Communities and Local Government. (2007) "Homes for the Future: More Affordable, More Sustainable," DCLG: London, UK.

Gerardi, Kristopher, Eric Rosenblatt, Paul S. Willen, and Vincent Yao. (2015) "Foreclosure Externalities: New Evidence," Journal of Urban Economics, 87(1), 42-56.

Harding, John P., Eric Rosenblatt, and Vincent W. Yao. (2009) "The Contagion Effect of Foreclosed Properties," Journal of Urban Economics, 66(3), 164-178.

Henderson, Steven R. (2015) "State Intervention in Vacant Residential Properties: An Evaluation of Empty Dwelling Management Orders in England," Environment and Planning C: Politics and Space, 33(1), 61-82.

Hillier, Amy E., Dennis P. Culhane, Tony E. Smith, and C. Dana Tomlin. (2003) "Predicting Housing Abandonment with the Philadelphia Neighborhood Information System," Journal of Urban Affair, 25(1), 91-106.

Immergluck, Dan. (2016) "Examining Changes in Long-term Neighborhood Housing Vacancy during the 2011 to 2014 US National Recovery," Journal of Urban Affairs, 38(5), 607-622.

(C)Southern Regional Science Association 2020. 
Mikelbank, Brian A. (2008) "Spatial Analysis of the Impact of Vacant, Abandoned, and Foreclosed Properties," Federal Reserve Bank of Cleveland.

Morckel, Victoria Chaney. (2013) "Empty Neighborhoods: Using Constructs to Predict the Probability of Housing Abandonment," Housing Policy Debate, 23(3), 469-496.

Morckel, Victoria Chaney. (2014a) "Predicting Abandoned Housing: Does the Operational Definition of Abandonment Matter?," Community Development, 45(2), 122-134.

Morckel, Victoria Chaney. (2014b) "Spatial Characteristics of Housing Abandonment," Applied Geography, 48, 8-16.

Paredes, Dusan and Mark Skidmore. (2017) "The Net Benefit of Demolishing Dilapidated Housing: The Case of Detroit," Regional Science and Urban Economics, 66, 16-27.

Scafidi, Benjamin P., Michael H. Schill, Susan M. Wachter, and Dennis P. Culhane. (1998) "An Economic Analysis of Housing Abandonment," Journal of Housing Economics, 7(4), 287-303.

Schilling, J. M. (2002) "The Revitalization of Vacant Properties," ICMA (International City/County Management Association), Washington, DC.

Spader, Jonathan, Jenny Schuetz, and Alvaro Cortes. (2016) "Fewer Vacants, Fewer Crimes? Impacts of Neighborhood Revitalization Policies on crime," Regional Science and Urban Economics, 60, 73-84.

Vyas, Nirali. (2016) "The Effects of Foreclosure-drive Vacant Properties on Crime in Trento," The College of New Jersey of Business Department of Economics.

Whitaker, Stephan and Thomas J. Fitzpatrick IV. (2013) "Deconstructing Distressedproperty Spillovers: The Effects of Vacant, Tax-delinquent, and Foreclosed Properties in Housing Submarkets," Journal of Housing Economics, 22(2), 79-91.

White, Michelle J. (1986) "Property Taxes and Urban Housing Abandonment," Journal of Urban Economics, 20(3), 312-330.

Zhang, Lei, Tammy Leonard, and James C. Murdoch. (2016) "Time and Distance Heterogeneity in the Neighborhood Spillover Effects of Foreclosed Properties," Housing Studies, 31(2), 133-148.

Zhang, Yang. (2012) "Will Natural Disasters Accelerate Neighborhood Decline? A Discretetime Hazard Analysis of Residential Property Vacancy and Abandonment before and after Hurricane Andrew in Miami-Dade County (1991-2000)," Environment and Planning B: Planning and Design, 39(6), 1084-1104.

(c)Southern Regional Science Association 2020. 


\section{A. APPENDIX A}

Table A.1: Estimation results for Models 1,2 and 3

\begin{tabular}{|c|c|c|c|}
\hline & Model 1 & Model 2 & Model 3 \\
\hline \multicolumn{4}{|c|}{ Variables for neighboring vacant houses and apartments with a high vacancy rate } \\
\hline VH50 & $d V H 50$ & $d V H 50(2)$ & $c V H 50$ \\
\hline VH100 & $d V H 100$ & $d V H 100(2)$ & $c V H 100$ \\
\hline VA50 & $d V A 50$ & $d V A 50$ & $c V A 50$ \\
\hline VA100 & $d V A 100$ & $d V A 100$ & $c V A 100$ \\
\hline VH50 & $-0.017^{* * *}$ & $-0.016^{* *}$ & $-0.007^{* *}$ \\
\hline VH100 & $-0.009^{*}$ & -0.000 & $-0.002^{*}$ \\
\hline DistVH & & & $0.074 *$ \\
\hline VA50 & $-0.012^{* *}$ & $-0.011^{* *}$ & $-0.009 * * *$ \\
\hline VA100 & -0.005 & -0.004 & 0.001 \\
\hline \multicolumn{4}{|c|}{ Control variables } \\
\hline FLevel & $0.009 * * *$ & $0.009^{* * *}$ & $0.009 * * *$ \\
\hline FArea & $0.027^{* * *}$ & $0.027^{* * *}$ & $0.028^{* * *}$ \\
\hline FArea ${ }^{2}$ & $-0.000^{* * *}$ & $-0.000 * * *$ & $-0.000 * * *$ \\
\hline Bedrooms & $0.014^{* *}$ & $0.016^{* *}$ & $0.015^{* *}$ \\
\hline Age & $-0.001^{* * *}$ & $-0.001 * * *$ & $-0.001^{* * *}$ \\
\hline$A g e^{2}$ & $0.000^{* * *}$ & $0.000^{* * *}$ & $0.000 * * *$ \\
\hline DistStation & -0.000 & -0.000 & -0.001 \\
\hline New & 0.012 & $0.015^{*}$ & 0.013 \\
\hline$F L 1$ & $-0.017^{* * *}$ & $-0.016 * * *$ & $-0.017^{* * *}$ \\
\hline South & $0.012^{* * *}$ & $0.013^{* * *}$ & $0.012^{* * *}$ \\
\hline Park & $0.023^{* * *}$ & $0.022^{* * *}$ & $0.023^{* * *}$ \\
\hline AutoLock & $0.030^{* * *}$ & $0.030^{* * *}$ & $0.030 * * *$ \\
\hline$A C$ & $-0.016^{*}$ & $-0.017^{* *}$ & $-0.017^{*}$ \\
\hline SharedBath & -0.025 & -0.023 & -0.021 \\
\hline UnitBath & $0.029^{* * *}$ & $0.029 * * *$ & $0.028 * * *$ \\
\hline AutoBath & $0.027 * * *$ & $0.025^{* * *}$ & $0.025^{* * *}$ \\
\hline Flooring & $0.010^{* *}$ & $0.011^{* * *}$ & $0.009 * *$ \\
\hline Pet & $0.031^{* * *}$ & $0.028^{* * *}$ & $0.031^{* * *}$ \\
\hline Available & $0.014^{* * *}$ & $0.014^{* * *}$ & $0.015^{* * *}$ \\
\hline SecurityCam & 0.007 & $0.008^{*}$ & $0.007^{*}$ \\
\hline CityGas & $-0.013^{* *}$ & $-0.013^{* *}$ & $-0.013^{* *}$ \\
\hline Box & $0.012^{* *}$ & $0.011^{* *}$ & $0.010^{* *}$ \\
\hline LuxApartment & 0.001 & 0.003 & 0.002 \\
\hline \multicolumn{4}{|l|}{ Fixed effects } \\
\hline Building structures (4) & $\mathrm{X}$ & $\mathrm{X}$ & $\mathrm{X}$ \\
\hline Districts $(81)$ & $\mathrm{X}$ & $\mathrm{X}$ & $\mathrm{X}$ \\
\hline Train/subway lines (13) & $\mathrm{X}$ & $\mathrm{X}$ & $\mathrm{X}$ \\
\hline Land-use zonings (8) & $\mathrm{X}$ & $\mathrm{X}$ & $\mathrm{X}$ \\
\hline Observations & 3806 & 3728 & 3691 \\
\hline$R^{2}$ & 0.9212 & 0.9217 & 0.9210 \\
\hline
\end{tabular}

The dependent variable is the logarithmic value of the monthly rental price of a rental housing unit. ***, **, and * indicate 1 percent, 5 percent, and 10 percent significance levels, respectively. White's robust standard errors are shown in parentheses. The results of the control variables are not shown in the table. $d V H$ and $c V H$ indicate a dummy variable and a count of neighboring vacant house(s), and $d V A$ and $c V A$ indicate those of neighboring apartment buildings with vacancy rates higher than 30 percent, respectively. Dummy variables $d V H 50$ and $d V H 100$ indicate a rental housing unit with at least one vacant house within $0-50 \mathrm{~m}$ and $51-100 \mathrm{~m}$, respectively. Dummy variables $d V H 50(2)$ and $d V H 100(2)$ indicate a rental housing unit with at least one vacant house in addition to the closest vacant house within $0-50 \mathrm{~m}$ and $50-100 \mathrm{~m}$, respectively. Dist VH is the distance to the closest vacant house. 
Table A.2: Estimation Results for Models 1, 2 and 3 with Finer Distance Bins

\begin{tabular}{|c|c|c|c|}
\hline & Model 1 & Model 2 & Model 3 \\
\hline \multicolumn{4}{|c|}{ Variables for neighboring vacant houses and apartments with a high vacancy rate } \\
\hline VH25 & $d V H 25$ & $d V H 25(2)$ & $c V A 25$ \\
\hline VH50 & $d V H 50$ & $d V H 50(2)$ & $c V H 50$ \\
\hline VH75 & $d V H 75$ & $d V H 75(2)$ & $c V H 75$ \\
\hline VH100 & $d V H 100$ & $d V H 100(2)$ & $c V H 100$ \\
\hline VA25 & $d V A 25$ & $d V A 25$ & $c V A 25$ \\
\hline VA50 & $d V A 50$ & $d V A 50$ & $c V A 50$ \\
\hline VA75 & $d V A 75$ & $d V A 75$ & $c V A 75$ \\
\hline VA100 & $d V A 100$ & $d V A 100$ & $c V A 100$ \\
\hline \multicolumn{4}{|c|}{ Variables for neighboring vacant houses } \\
\hline \multirow[t]{2}{*}{ VH25 } & $-0.024^{* * *}$ & $-0.064^{* * *}$ & $-0.022 * * *$ \\
\hline & $(0.007)$ & $(0.018)$ & $(0.006)$ \\
\hline \multirow[t]{2}{*}{ VH50 } & $-0.011^{* *}$ & -0.007 & -0.002 \\
\hline & $(0.005)$ & $(0.008)$ & $(0.003)$ \\
\hline \multirow[t]{2}{*}{ VH75 } & -0.004 & -0.000 & -0.003 \\
\hline & $(0.005)$ & $(0.006)$ & $(0.002)$ \\
\hline \multirow[t]{2}{*}{ VH100 } & $-0.013^{* *}$ & 0.000 & -0.001 \\
\hline & $(0.005)$ & $(0.005)$ & $(0.002)$ \\
\hline \multirow[t]{2}{*}{ DistVH } & & 0.066 & \\
\hline & & $(0.041)$ & \\
\hline \multicolumn{4}{|c|}{ Variables for neighboring apartments with a high vacancy rate } \\
\hline \multirow[t]{2}{*}{ VA25 } & $-0.021 * * *$ & $-0.016^{* * *}$ & $-0.017 * * *$ \\
\hline & $(0.006)$ & $(0.006)$ & $(0.006)$ \\
\hline \multirow[t]{2}{*}{ VA50 } & $-0.009^{*}$ & -0.009 & $-0.007^{*}$ \\
\hline & $(0.005)$ & $(0.005)$ & $(0.004)$ \\
\hline \multirow[t]{2}{*}{ VA75 } & $-0.015^{* * *}$ & $-0.014^{* * *}$ & -0.002 \\
\hline & $(0.005)$ & $(0.005)$ & $(0.003)$ \\
\hline \multirow[t]{2}{*}{ VA100 } & $0.009^{*}$ & 0.006 & $0.005^{* *}$ \\
\hline & $(0.005)$ & $(0.005)$ & $(0.002)$ \\
\hline Observations & 3806 & 3728 & 3691 \\
\hline$R^{2}$ & 0.9219 & 0.9223 & 0.9217 \\
\hline
\end{tabular}

The dependent variable is the logarithmic value of the monthly rental price of a rental housing unit. ${ }^{* * *},{ }^{* *}$, and * indicate 1 percent, 5 percent, and 10 percent significance levels, respectively. White's robust standard errors are shown in parentheses. The results of the control variables are not shown in the table. $d V H$ and $c V H$ indicate a dummy variable and a count of neighboring vacant house(s), and $d V A$ and $c V A$ indicate those for neighboring apartment buildings with vacancy rates higher than 30 percent, respectively. Dummy variables $d V H 25, d V H 50, d V H 75$, and $d V H 100$ indicate a rental housing unit with at least one vacant house within 0-25m, 26-50m, 50-75m and 75-100m, respectively. Dummy variables $d V H 25(2), d V H 50(2), d V H 75(2)$, and $d V H 100(2)$ indicate a rental housing unit with at least one vacant house except the closest vacant house within 0-25m, 26-50m, 50-75m and 75-100m, respectively. DistVH is the distance to the closest vacant house.

\section{B. APPENDIX B}

Although data regarding sale prices and the geographical distribution of residential properties throughout the municipality are required to precisely estimate the impact on property tax income, we only have samples of the rental apartment units used in the hedonic estimation, and thus, we perform the following steps to estimate the increase in property tax income.

1. We assume that the relative property price differences across districts in the munic- 
ipality are the same as the relative rental price differences across these districts. ${ }^{19}$ Accordingly, we regress the rental prices on the district dummy variables by using our data to estimate the relative property price differences across districts.

2. The statistics of the annual incomes from property taxes and city planning taxes can be obtained up to the municipality level. Using income data from taxes and statistics for the number of households in each district in the Toshima municipality, the average property tax income per household in each district can be computed by considering the relative price difference calculated in step 1.

3. We assume that the geographic distribution of rental housing units in our data is the same as the actual geographic distribution of property units in Toshima municipality. Then, we estimate the number of households that exist within $50 \mathrm{~m}$ and within $50-100 \mathrm{~m}$ of vacant houses with each particular condition in each district.

4. The change in property tax revenue due to addressing vacant houses with condition $j$ in the municipality is estimated as follows: $\Delta R e v_{(j)}=\sum_{d} \overline{\operatorname{Rev} v_{d}}\left(\widehat{\theta_{50(j)}^{4}} N_{d(j)}^{50}+\widehat{\theta_{100(j)}^{4}} N_{d(j)}^{100}\right.$, where $d$ indicates the district; $\overline{R e v_{d}}$ is the average property tax per household in district $d$ as calculated in step $2 ; \widehat{\theta_{50(j)}^{4}}$ and $\widehat{\theta_{100(j)}^{4}}$ are the parameters estimated in Model 4, i.e., $\widehat{\alpha_{50(j)}^{4}}$ and $\widehat{\alpha_{100(j)}^{4}}$ for the effects of particular condition $j$ and $\widehat{\gamma_{50(j)}^{4}}$ and $\widehat{\gamma_{100(j)}^{4}}$ for the effects when the status of condition $j$ is "unknown," respectively; and $N_{d(j)}^{50}$ and $N_{d(j)}^{100}$ are the estimated numbers of households within $50 \mathrm{~m}$ and $50-100 \mathrm{~m}$ of vacant houses as calculated in step 3, respectively. If vacant houses with condition $j$ are addressed, the property tax income is expected to increase by $\left|\Delta \operatorname{Rev}_{(j)}\right|$.

\footnotetext{
${ }^{19}$ The theoretical sale price is the expected discounted value of the rental revenue (or imputed rent) in the future. According to the theory, the sale price is directly proportional to the rental price, given that the expectations of discount factors, such as the interest rate, depreciation rate of rent and property tax rate, are constant in the future.
}

(c)Southern Regional Science Association 2020. 